\title{
Application of Game Theory in Middle-Management: A Military Historical Study of the Role of the Middle-Manager as a Correlated Equilibrium Factor in the Decision-Making Process
}

\author{
Quentin Commine \\ commine@unistra.fr \\ University of Strasbourg, France \\ Jérémie Aboiron \\ aboiron@neofaculty.org \\ Neofaculty Europe, France \\ https://doi.org/10.51137/ijarbm.2021.2.1.5
}

\begin{abstract}
The role of the manager, defined by innumerable scientific publications, is only rarely seen through the prism of game theory and its notions of equilibrium allowing decision-makers to optimize situations. The role of the middle-manager, mindful of the human factor and respectful toward his mission shall lead to a virtuous balance, can be defined in game theory as a correlated equilibrium in the sense of the game theorist Robert Aumann. Indeed, this kind of equilibrium goes further than the Nash equilibrium by introducing the notion of a common game and an intermediary embedded in the decision-making process and getting the strategy from his superiors to translate it to his subordinated staff. We use two military historical illustrations to illustrate this concept: the case of the Auftragstaktik refers to Sherman's "march to the sea" while the study of Lee's defeat at Gettysburg refers to the necessity of having capable subordinated staff to maximize an outcome. Throughout this study, we show and formalize the essential role of the middle-manager in the elaboration of effective decisions and processes.
\end{abstract}

Keywords - correlated equilibrium, decision-making, game theory, middle-manager, military history, strategy.

\section{Introduction}

Within the execution of a production process, the manager poses as the basic decision-making nucleus from which the major orientations given by the higher positions are translated in the direction of the executing personnel. This, to better fulfill the settled objectives and by using the best of each subordinate's potential. The manager is therefore « responsible for achieving business objectives, especially in declining all of these objectives to his employees and in supporting their achievement » (Desmarais et al., 2010).

Developing a project often requires full adequacy of the means and thoughts available to the manager but also the interaction of three great virtues which, like a tweet Jeff Weiner (CEO of Linkedln) wrote on July 21, 2014 (see in Steiber \& Alange, 2015), can be summarized as: "See far, stick

Application of Game Theory in Middle-Management: A Military Historical Study of the Role of the Middle-Manager as a Correlated Equilibrium Factor in the Decision-Making Process 
to it, find pleasure." This quote aptly illustrates the objective to be achieved by a manager, symbolized by these three qualities for his collaborators. This is a practical reflection of Mintzberg's (1984) ten principles of management, which can be classified into three broad categories:

- Interpersonal roles: in the case studied we will see that the notion of specific connection is linked to managerial practice.

- Roles of information: the manager is here seen as the "master of the game" disseminating information to all.

- Decision-making roles: as negotiator and regulator, and vision producer.

Through the prism of Mintzberg's theory, the conciliatory aspect of the manager seems essential and essential to the smooth running of processes.

These three fundamental and emblematic logics of the new way of managing are totally part of this logic of "hyphen". Indeed, "see far" is correlated to the ability of a manager to explain the long-term goal of a project. "Sticking to it" shows a team leader's ability to set intermediate goals and allow his team to progress gradually, making everyone capable of reaching the final goal. "To know how to find pleasure" refers to the human dimension of a manager whose fundamental concern must be to motivate his "troops" and to inspire the desire of being successful by encouraging the project of his entire team. These fundamental logics refer to a concept also present in game theory, that of equilibrium.

Game theory makes it possible to model human behaviors in a simple way from a rational angle and operates according to a logic of equilibrium to achieve. That leads to our main research question: can the equilibrium correlated with the meaning of $R$. Aumann's theory be used to illustrate the benefits of the manager's intellectual freedom and how to illustrate this freedom in the frameworks inherent in mediation and the freedom of action of the manager?

Four intermediate questions are asked to answer this main question: how to define a correlated equilibrium in a managerial situation? What can a correlated equilibrium bring in terms of results? How does this concept apply to the managerial problematic of mediation? How can we experience this concept in terms of freedom of action and hierarchical benefits within the decision-making process? (Historical examples of military applications, see Mongin, 2008).

Nevertheless, the current existing literature do not consider sufficiently the role of the intermediate manager. Firstly, it is necessary to carry out a state of the art by the synthesis of articles representative of the study axis, these making it possible to obtain a formalization of the correlated equilibrium model. It is therefore a question of studying a top-down vertical strategic harmonization "Superior -Manager- Subordinate". Once this model is established, it is shown that the role of "advisor" and "motivator" of the manager as "middle-point". After having explored the current state of the art of the addressed object, we will define our methodology before studying two historical cases in order draw game theoretical assets of the role of a middle manager.

Application of Game Theory in Middle-Management: A Military Historical Study of the Role of the Middle-Manager as a Correlated Equilibrium Factor in the Decision-Making Process 


\section{Literature review}

According to Desmarais et al. (2010), the manager poses as a translator of the wishes of his hierarchy, oscillating between intellectual autonomy and a simple transmission of orders. The role of the manager can be grasped by its content through two fundamental conceptions: the functionalist conception of Fayol (1916) or the interactionist and emergent approach of Mintzberg (1973). Whatever the approach, the manager always remains a "hyphen" between the upper hierarchy and the subordinate functions. He sometimes faces more exogenous constraints to bring about change (Averous et al., 2004), harmonizing all the vectors of commitment within his team by actions on the organization, methods and on optimizing the human resource (notably by its motivation). The manager's actions aim in the expression of broad outlines and long-term goals as intermediaries to reach the goal. Lacan (2016) shows us that management is evolving and that "the modern period is now over". The model carried so far by a thought pattern is now "saturated" and implies for the new manager to develop an effective "working together", concerned with the human element (Lacan, 2016).

A balance can be translated as the convergence of the various rationalities of the actors forming part of a situation of interactions, defined as a "game". The balance defines an optimal decision for each actor resulting in a situation satisfying all the players in a relative way: none has any interest in changing its strategy, especially regarding what the opponent does (Walliser, 2002). The result, sometimes far from being the best that can be obtained from a global point of view of "social welfare", does not therefore systematically correspond to the sense of a Pareto optimum. This definition of equilibrium in game theory corresponds to one of the most famous and most used: the Nash equilibrium. Indeed, John Forbes Nash, using the property of fixed-point theorems, notably that of Kakutani which allows -in the domain of a set-valued function and defined on compact convex in a space, called Euclidean- to have a point such that $f(x)=x$ (see Kakutani, 1941), the socalled "possible limits" equation on an application of $\mathrm{R}$ on $\mathrm{R}$. For any function admitting one or more fixed points, it is for example the intersection of the curve of the function studied with the right $y=x$.

The achievement of a balance also lies in the context of the game (static or dynamic) and in the beliefs of each player that can be multiple and are mathematically modeled by utility functions and whose occurrence is intrinsically linked to this. Same final utility can be expressed in a set or probabilistic manner. Beliefs being of several types (Walliser 2002):

- Structural: wonder about the game itself and especially the other players and their possible decisions and their motivations (so we wonder what pushes the other to make this or that decision).

- Factual: we consider the past game, and we try to determine a future trend.

- Strategic: elaboration of future "courses of action" based on the characteristics of the game, of oneself and of the different other players.

Application of Game Theory in Middle-Management: A Military Historical Study of the Role of the Middle-Manager as a Correlated Equilibrium Factor in the Decision-Making Process 
The structural dimension seems to be interesting in the study of the managerial context when one seeks to grasp organizational issues. It is also the position of the manager in the organizational structure which confers on him the mediating functions. Underlying and knowing the rationality of the game and the players allows identifying four main types of results (Walliser 2002):

- Elimination of dominated strategies at the level of the actor and this, successively in the different matrices of games obtained. All players doing the same, we ultimately get a set of strategy can under additional data condition - to give a balance. (Tan-Werlang 1988).

- Each player defines his best answer to the strategy of others (rationalized equilibrium in the sense of Bernheim (1984-196) and Pierce (1984)).

- The case of the Nash equilibrium is essentially based on the oneday personal anticipation of the strategies (and their occurrence) of the other and represents - in a sequential way - an equilibrium destined to being realized in the unfolding of a game.

- If the set of beliefs of the players results from a common "prior distribution", we obtain a balance based on a distribution of randomness and probabilistic issues of the game. An external agent defines the best answer (or at least recommend it) for each player facing a given situation. This exogenous arbitration is only useful if all players are willing to follow its recommendations. This last assertion is suited to the managerial problem and it is now necessary to develop it in defining the notion of correlated equilibrium. This important notion for our study was introduced for the first time by Aumann (1987).

Having studied a wide spectrum (and over a long period) of the different components of game theory, Aumann deals with games, both cooperative and non-cooperative, to bring to fruition his concept of equilibrium (Schmidt, 2006). Concerning cooperative games, it highlights the existence of "structures of coalitions" that can be represented with an identical function (Aumann and Drèze, 1976) also underpinning an endogenous vision of coalitions influenced by the logic of social communication (Greenberg 1990).

Regarding non-cooperative games, we are dealing with a set of mixed strategies, this time paired with the beliefs of each player. The lack of information between the players pushes them to rely on external decision elements and especially on common knowledge, accessible to all players in the same way. The major difference between a correlated equilibrium in the sense of Aumann and Nash equilibrium lies in the "non-self-fulfilling" side of the correlated equilibrium, the latter being based on a notion of common knowledge and not on a notion of belief and experience. The correlated equilibrium thus often makes it possible to obtain a solution closer to optimality than a simple Nash equilibrium, and this, even if the Nash equilibrium is a correlated equilibrium form. Instead of observing each player finding his solution, we consider the solution of the game and the respective beliefs of the players to get there.

Application of Game Theory in Middle-Management: A Military Historical Study of the Role of the Middle-Manager as a Correlated Equilibrium Factor in the Decision-Making Process 
This definition easily echoes the human definition of the manager, who must federate the energies and make the best of each person; he acts on beliefs to achieve the most optimal solution of games. We can therefore question the nature of a correlated equilibrium to reach a managerial solution.

\subsection{Illustration of the role of manager as "middle-point"}

Stimec (2008) shows us that in many cases, the manager is in a position of mediation because of multiple facts related to concrete situations, important in game theory, that we can mention: knowledge of the actors and their beliefs, equity in the information from the actors and big overview, proximity on the ground and exchanges with the actors (bilateralism).

The manager has a real role of conciliator between the functions that are in his "area of action". The manager's overall knowledge of the "field" effects of the various agents allows him to play a mediating role. This mediation can be horizontal in the case of confrontations between two members of the same team; it can also be vertical, in the case of a conflict between the executing parties and the hierarchy (case of the intermediate manager trying to calm a disagreement between a subordinate and a higher level executive).The conciliations of the manager often aiming to find an intermediate balance between the higher leader and the employee, there are two great illustrations: the regulation by the manager and the freedom of action for the manager illustrated by the command on purpose.

The manager must therefore act in the negotiating area of the higher leader to sometimes modify its initial plan (convince him that "doing less or doing it in another way can -sometimes- lead to do more and better" and act in the motivation area of the executing personal (motivation to do more, without risks of "burning out"). This, in giving recommendations and incentives to each agent to obtain an optimal game, the manager thus poses as a factor of correlated equilibrium.

In another order of ideas, the manager has a real role of conciliator between the functions that are in his "area of action". The manager's overall knowledge of the "field" effects of the various agents allows him to play a harmonizing role. This mediation can be horizontal in the case of confrontations between two members of the same team; it can also be vertical, in the case of a conflict between the executing parties and the hierarchy (case of the intermediate manager trying to calm a disagreement between a subordinate and a higher-level executive). The conciliations of the manager often aim at most to find a balance between the manager and the employee. These facts can be described by using two big illustrations: the freedom of action for the manager illustrated and the efficiency of "management talks".

Achieving this virtuous equilibrium leads to obtaining a decision-making "pivot" that becomes a factor of flexibility and tactical coordination. These two concepts are reflected by the practice of command on objective (Auftragstaktik) which leaves a freedom to the intermediate superior in the means used to reach the settled objective. The other example is the creation of this balance by obtaining competent intermediate subordinates and inte-

Application of Game Theory in Middle-Management: A Military Historical Study of the Role of the Middle-Manager as a Correlated Equilibrium Factor in the Decision-Making Process 
grating their recommendations as a part of the decision-making reflection. These two principles are illustrated in the following historical case-studies, after their introduction in the next part of this paper.

\section{Methods \& Materials}

The studies established in this article also refer to various and common concepts in game theory that can be parallel to the notion of correlated equilibrium, such as Nash equilibrium or theory of common knowledge. Thus, the notion of equilibrium in game theory will be introduced before adding the "Aumanian" dimension. We can thus affirm that this article mixes a mainly post-positivist approach, seeking to validate a strategic theory by the study of facts on the ground and an analysis of historical fact. The extreme simplification of the mathematical data introduced is explained by the focus of this article on a practical application of management theory.

The study of the military fact relating to the historical illustration of the strategic benefits of the freedom of action left to a leader. The originality of the study of historical facts from military history has a twofold advantage. The first advantage lies in the military fact itself. Indeed, war requires effective action in a context that can be tactical, operational, or even strategic, these scales recalling the different decision-making levels of a generic organization. The second advantage of the study of a fact taken from military history is its "theorizing in strategic thinking", particularly adapted to the field of game theory, and yet rarely used. Although the concept of decision making can be found in all managerial situations and not especially within the armed forces, the military decision-making process describes perfectly how the intermediate military commander plays a role as an advisor to help his own superior to make optimal decisions. It also perfectly describes how the intermediate commander motivates his troops in giving the adapted "inputs" in terms of incentives.

The case study of General Sherman's "Walk to the Sea" seems to be a good historical example, illustrating the notion of "Auftragstaktik" leaving the intermediate leader with the means to succeed in his mission and making him the intermediary proposing his superior the best way of fulfilling its whole objectives and imposing this way to his subordinate staff. The study of this historical fact, methodologically rare phenomenon, thus also brings a significant originality to this analysis.

The second case study of the opposition between Lee and Longstreet at the Battle of Gettysburg is a model of its kind aimed at showing the need to have a competent intermediate "manager" and that once this "balancing factor "created and set in place, it is necessary to use it to gain the most from the situation. For commanders, talking with capable intermediate leaders within the framework of a decision-making process is a way of setting a correlated equilibrium.

From a purely methodological point of view, this case study partly fits into Yin's (2003) definition that a case study can be illustrative and does not need to go "on the ground". Nevertheless, Yin (2003) explains that a case study

Application of Game Theory in Middle-Management: A Military Historical Study of the Role of the Middle-Manager as a Correlated Equilibrium Factor in the Decision-Making Process 
must be "contemporary", normally excluding the historical example. This statement is clearly nuanced by Wieviorka (1992): "It is not the seniority or the contemporaneousness of the case that brings it out of one or the other of these social sciences but rather the way in which it is analyzed and interpreted to be useful to the sociologist to isolate a phenomenon or a sociological category, or to elaborate new concepts and theoretical tools ". Wieviorka (1992), introducing a sociological and historical dimension, shows that "several case studies are generally necessary". These historical case studies by the prism of game theory follow this methodological hybridization.

\section{$4 \quad$ Results}

Military history is rich in situations of balanced equilibrium because of the hierarchical interweaving and the principle according to which the subordinate must be force of proposal for his superiors and that the military leader in the broad sense - must be capable of "acting as a thought leader, diffusing serenity to his troops" and" knowing how to count on intermediate leaders " by constituting a correlated equilibrium in getting the best from their capabilities.

\subsection{Case Study No. 1: the Auftragstaktik (Shamir, 2010), the case of Sherman's march to the sea (November 15 to December 21, 1864).}

Of Prussian origin and completed especially during the defeat of France in 1870 , this concept is today at the base of many doctrines of modern military command. This type of "command on purpose" comes under another fundamental principle: the principle of subsidiarity. The intermediate leader receives his orders from his superior, who gives him the overall direction and goal to achieve. In this type of command, the intermediate leader has full discretion in the way he manages his subordinates to carry out his mission. The intermediate leader thus embraces the orders of his hierarchy and settles his action to get maximum results from the capabilities of his team to complete the mission. This concept also allows him to better carry out the constraints of his hierarchy by asserting his own intellectual autonomy and in being really embedded in the decision-making process.

The example studied is about the Civil War. This choice is motivated by the interesting aspect of "tactical laboratory" carried by this conflict where "the extreme similarity between the two armies makes it possible to reason the war by isolating the parameters other than the decision of the commanders" (Yakovleff, 2006). Indeed, both sides come from the same country and have a quite similar culture and show some equivalent military characteristics. This example allows to focus on the pure consideration of facts and interactions under neutral "experimental" conditions. Notwithstanding the critical dimension of such an operation, which could be easily questioned about its ethical aspects, this operation carried out by the general William Tecumseh Sherman (1820-1891) is a model in the field of Auftragstaktik. We

Application of Game Theory in Middle-Management: A Military Historical Study of the Role of the Middle-Manager as a Correlated Equilibrium Factor in the Decision-Making Process 
illustrate this case quoting the exchange between Generals Grant and Sherman from the study done by Rosseels (2012).

Following the capture of Atlanta in September 1864, Sherman commanded General Ulysses Grant to conduct a large-scale maneuver in Confederate country across Georgia, South Carolina, and North Carolina to come on the rear of Lee's army, which stood up to Grant's troops in Virginia. The goal of the "march" is mainly to progress towards Savannah, causing irreparable damage to the enemy wherever he is. In order to reach an optimal endstate, Sherman proposes an operation including a policy of devastation of the rear in the crossed zone to inflict such losses that the enemy would be deprived of the economic and tactical means to continue the fight effectively, in addition to an effect on the morale of the southern troops.

From Rosseels (2012, p.10), here is Grant's written order to Sherman: "It is my design, if the enemy keeps quiet and allows me to take the initiative in the Spring Campaign to work all parts of the Army together, and, somewhat, towards a command center. I propose to move against Johnston's Army, to make it easier to get to grips with the inside of the world the work it is desirable to have your way of operation ». Here, General Grant leaves it to General Sherman to carry out his task as he sees fit by giving only the general concept of operations, leaving him in the same position to manage his troops adequately to fulfill his mission. Sherman takes this initiative into account, according to his answer: "That is not a common act, a convergent one on a common center, looks like enlightened war ...I will not let side issues draw me off from your main plan in which I am to knock Joe Johnston and do as much damage to the resources of the enemy as possible" (Rosseels, 2012). With these words, Sherman reassures his superior (Grant) and assures him that he has understood what is expected of him. The concept of "enlightened war" shows that the fact of leaving latitude to the intermediate leader allows him to propose innovative solutions. Unfortunately, in this case will this enlightenment be the cause of the devastation of a big part of the southern United States. All these exactions are made to allow Sherman's army to "live on the enemy" and therefore not to suffer the vagaries of logistics but will be a key point for Sherman to seize Savannah on December the 20th. This success is often regarded as paramount to Grant's final victory.

Thus, the concept of correlated equilibrium is illustrated here in the sense that Sherman adapts his action to the wishes of his superior by proposing his own initiatives and "motivates" his troops by encouraging them to live on the enemy, even if these encouragements will be limited in Sherman's Special Field Orders, No. 120. This way of commanding leads to a synergy between the troop and his intermediate commander by the adequacy of utilities (in a game-theoretic way).

\subsection{Case Study No. 2: the Lee-Longstreet relationship during the Battle of Gettysburg.}

The Battle of Gettysburg (July 1-3,1863) is considered by many publications as the turning point in the Civil War and results in the defeat of the Army of Northern Virginia - commanded by Robert E. Lee - the Potomac Army,

Application of Game Theory in Middle-Management: A Military Historical Study of the Role of the Middle-Manager as a Correlated Equilibrium Factor in the Decision-Making Process 
commanded by George G. Meade. From April 27 to May 6, 1863, "Lee's Perfect Battle" or Chancellorsville's victory against General Hooker's Union troops took place. This overwhelming victory puts the southern general in confidence and directs his tactical vision for the ensuing battle at Gettysburg. One of the best-known causes of this southern defeat (which turns out to be decisive for the rest of the war) is the disagreement between General Lee (Commander in Chief) and General James Longstreet. Although considered by the former as his "old war horse" and one of his most reliable generals, Longstreet will disagree with Lee's tactics during this battle. In particular, he issued large and serious reservations on the third day of the battle, about the "Pickett charge".

Lee, determined to drive the northern defense of the Potomac army into its center, orders Longstreet to charge 12,500 Confederate soldiers after a preparation consisting of an artillery strike upon the northern positions. The assault, carried out in an open field and facing an enemy who had prepared effectively for this offensive, resulted in a disaster for the Confederate troops: about half of the soldiers participating in this charge then died.

Longstreet will only accept this order reluctantly and after attempting to expose this to Lee, who then refuses Longstreet's recommendations, the latter preferring an attack by the left flank of the Potomac Army, will later claim that "Lee should have employed another officer who would have had more confidence in his plan" (Wert 2015). The fatal outcome of this unfortunate offensive is found in the words of Pickett, whose division then came to lead this assault murderer: "General, I'm ruined, my division is gone; it is destroyed "(Wert, 2015).

In this case, history shows that the most important general of the confederation lost this battle because of a lack of confidence in Longstreet's point of view. By not basing himself on the advice of a capable intermediate leader who tried to propose an alternative course of action (which was to realize the initial plan by a less incisive but more cautious offensive), Lee takes the wrong decision and leads his army into defeat. The northerners do the exact opposite: Meade knows how to rely on his subordinates and anticipates all the actions of the Southerners. He also makes all his decisions in taking into account all tactical advice. Gettysburg was not only a defeat for the Confederate army, but it is also the pivotal point of the Civil War, to the advantage of the North.

\subsection{Application to managerial issues}

In the wake of a problem of the "principal-agent" type, the manager can, as a hyphen, allow to avoid another type of deleterious problem in the execution of a game thus modeling a managerial situation. Indeed, the problem of the relationship between the client and the subordinate can be illustrated with the help of the "prisoner's dilemma", a classic thought experiment of game theory (Baudry, 1993). This modeling can be summed up by the fact that, not knowing the exact interlocking of the thinking of the higher hierarchical positions, the subordinate positions does not try to execute the orders in the best possible way to "preserve" him. This situation necessarily leads

Application of Game Theory in Middle-Management: A Military Historical Study of the Role of the Middle-Manager as a Correlated Equilibrium Factor in the Decision-Making Process 
the higher positions to doubt his subordinate and to take precautionary measures to prevent any risk of default. This entails additional control costs for the higher positions and additional constraints for the subordinate positions, this lowering everyone's earnings and leading to a non-optimal balance compared to that which would be obtained in a cooperative game.

We now formulate the concept of correlated balance in management. At first, there are two types of correlations: public correlation and private correlation. In the first case, all players witness the strategies proposed by the intermediary. In the second, the recommendations on the actions and the effects to be obtained are given to each player, in a particular way. The correlation can be formalized as follows:

Let $\mathrm{G}$ be a game in normal form, possessing a set of strategies $\mathrm{s}$, included in a set $S$ with $s \in S$. These strategies are given by the mediator under a formalization following a law of type $\pi$. The game is played as follows:

Step 0: the mediator draws a strategy $\mathrm{s} \in \mathrm{S}$ and assigns it according to $\pi$ to each player. The Ombudsman therefore controls the root of the extensive representation tree of $\mathrm{G}$.

Step 1: Players play their strategies in $\mathrm{G}$.

Example in management: « reassuring » management:

Given two players in G:

$\mathrm{J1}$ : a higher leader whose utility function is not risk averse and who tries to exert a strong control over his employees.

Two strategies are available:

s.i1: "putting pressure"; s.i2: "trusting the employee"

J2: a very efficient employee but not very resistant to the hierarchical pressure, having the possibility to anticipate the pressure of his superior. Two strategies exist:

s.j1: "getting stuck in it"; s.j2: "going through"

The manager $(\mathrm{M})$ acts as an intermediary. Without intervention of $M$, we observe the following gain matrix:

Tab. 1: Two players, two strategies: an equilibrium that can be optimized.

\begin{tabular}{|l|l|l|}
\hline J1 & s.i1 & s.i2 \\
J2 & & \\
\hline s.j1 & $(3 ; 4)$ & $(5 ; 4)$ \\
\hline s.j2 & $(4 ; 4)$ & $(4 ; 2)$ \\
\hline
\end{tabular}

Without the intervention of the manager, the higher leader has every interest in opting for the dominant strategy of "putting pressure", the latter offering the MaxiMin favorable. This decision is also because of the wellknown phenomenon of "adverse selection" and of the principal-agent relationship between the higher leader and his employee. The employee, mindful of its performance- opts for the strategy of "getting stuck in it" and because of his own ignorance of the higher leader's way to control how the job is being done. This leads to equilibrium in s.i1 / s.j1 with an overall gain of 7 . This situation can be optimized to obtain a higher overall gain and this is the goal of a managerial practice (Fernandez, 2013).

Application of Game Theory in Middle-Management: A Military Historical Study of the Role of the Middle-Manager as a Correlated Equilibrium Factor in the Decision-Making Process 
We introduce (M). Its action may be of two types: public or private correlation. In the first case, players are aware of all (M) recommendations for each of them. This is the case of a corporate strategy such as those set up during seminars or because of the indirect action of professional meetings. In the second, the strategies specific to each one come in the form of "managerial advice and incentives".

The adoption of one or the other type of correlations makes it possible, in the case described below. this deviates the equilibrium strategy on the pair s.j1 / s.i2 and makes it possible to obtain an overall gain of 9, corresponding to the substantial gain related to better professional practices allowing more well-being at work and especially more freedom of action for an efficient subordinate in his job.

It can therefore easily be concluded that professional talks and that the "harmonization of the wills" produce the best results. Cooperation, induced by the application of common rules and strategies defined for each in the common space, makes it possible to optimize the equilibrium (see Walliser, B. 1989).

The correlated equilibrium represents the manager who knows the ins and outs of each of the parties involved in the decision and execution process. He knows what the problems are related to the execution of a task for the personnel in charge of doing it and knows is proper limits. The manager is particularly aware of the point of rupture of his human resource. Knowing the core superior's intention, he can find an optimistic solution to the game to reduce the constraints of the "down" stage while meeting the requirements of the "high" stage. Aumann's concept of correlated equilibrium therefore applies perfectly to the essence of management.

\section{Discussion}

Aumann's correlated equilibrium - explained in a deliberately simplistic way in this article - perfectly models the role of the manager and the "intermediate" leader.

Without the autonomy that Grant gived Sherman, Sherman could not have done this "walk" with the dramatic (and controverted) success he is credited with. If Lee had used Longstreet's conciliatory role in Gettysburg and had not focused on his plan because of his previous successes and the deaths of the 6500 men of "Pickett's Charge" would have been avoided. The purpose of this example is not to consider the rightfulness of Longstreet advice. It is more interesting to focus on the lack of decision-making talks and the way Lee must deny Longstreet's incentives.

The counterpoint of these results must nevertheless be qualified by the very limits of game theory: the rationality of agents. Getting a correlated equilibrium implies indeed a perfect rationality of the players and of the intermediate agent. The works of Simon (1986 in particular) show a blended rationality because of the limited amount of information and possibilities the decision maker can possess and consider. Thus, the manager is subject to the same "fluctuation" of rationality just like any other "player" (Simon, 1986).

Application of Game Theory in Middle-Management: A Military Historical Study of the Role of the Middle-Manager as a Correlated Equilibrium Factor in the Decision-Making Process 
Considering this fact, the effect can be the opposite of a balance that benefits everyone. The manager can also be very criticized as in Buscatto (2002). For example, considering the example of the thought experiment of the "zealous leader": in this case, the intermediate leader places himself on the exclusive side of the upper hierarchy and do not bring any incentive to the subordinates who also loses direct contact with the higher leader.

Conversely, the case of an intermediate leader who appears too close to the subordinate personal present the case of a "demagogue manager" who drastically reduces the gains of the higher leader. The propensity of players to obey has also to be considered. Indeed, this propensity varies according to the considered environment. The use of the military example in this study minimizes the "risk" of disobedience due to the particularities of the military environment. As is, for example, the usefulness of players and their risk aversion, it is possible to model each player's propensity to obey. Although military examples have been used in this paper because of the top-down military quintessential way of deciding, the subject can thus be extended to more theoretical studies verging on development and modeling in the managerial framework, or to more localized applications relating to managerial situations or organizations.

\section{Conclusion}

This article shows that the notion of correlated equilibrium is greater in terms of collective gains than that of Nash equilibrium because of the existence of exogenous recommendations. The manager in his vertical involvement (as the military leader of the example studied) is a link between the wishes of his hierarchy - sometimes he must advise at best on how to revise some directives that that could be too difficult to implement- and its subordinate staff he must motivate and provide the most favorable conditions for the realization of the mission.

Unlike a "self-fulfilling" Nash equilibrium, which is rarely optimal, the correlated "Aumannian" equilibrium is often optimal because of the increasing of the overall gain and allows greater spontaneity by the knowledge of the players and of the terrain owned by the intermediate leader. In addition, following the recommendations of an intermediary leader with an overview generally allows "to clean up" interprofessional relationships and from a "game-theoretical" point of view maximizes the overall gain. This practice seems to be an optimization of the decision and execution function, justified, and demonstrated by game theory. Reaching a correlated equilibrium maximizes the overall gain and illustrates the benefits of total managerial freedom.

Indeed, we can conclude that this freedom of action allows the middle manager to have a role as a "middle-point" between executive functions and lower production functions by allowing the middle-manager to blossom in maximizing his decisional margin to meet the strategic objectives of the organization.

Application of Game Theory in Middle-Management: A Military Historical Study of the Role of the Middle-Manager as a Correlated Equilibrium Factor in the Decision-Making Process 


\section{$7 \quad$ References}

Aumann, R., \& Drèze, J. (1974). Cooperative games with coalition structures. International Journal of Game Theory 3(4), pp. 217-237.

Aumann, R. (1987). Correlated equilibrium as an expression of bayesian rationality, Econometrica 55(1), pp.1-18.

Averous, B., \& Averous, D. (2004). Mesurer et manager la qualité de service, INSEP CONSULTING éditions, Paris.

Baudry, B. (1993). Partenariat et sous-traitance: une approche par la théorie des incitations, Revue d'économie industrielle, $n^{\circ} 66,4^{\text {ème }}$ trimestre 1993, pp.51-68.

Broda, J. (1988). Le syndrome des «3 $P »$ : pression horaire, pression hiérarchique, pas de perspective professionnelle, Sociologie du Travail 30(1), pp. 19-36.

Buscatto, M. (2002). Des managers à la marge: la stigmatisation d'une hiérarchie intermédiaire, Revue française de sociologie 43(1), pp. 73-98.

Desmarais, C., \& Abord de Chatillon, E. (2010). Le rôle de traduction du manager: Entre allégeance et résistance. Revue française de gestion 36(205), pp.71-88.

Dugundji, J., \& Granas, A. (1982). Fixed Point Theory, PWN Polish Scientific Publishers, Varsovie

Fayol, H. (1916). Classics of organization theory, Moore Publishing, Oak Park, IL USA.

Fernandez, A. (2013). Le chef de projet efficace: 12 bonnes pratiques pour un management humain. Editions Eyrolles, Paris.

Forges, F., \& Renault, J., \& Sorin, S., \& Vieille N. (2006). Théorie des jeux, le prix Nobel pour les travaux de R.J. Aumann, Bulletin de liaison de la SMAI 79, pp 47-70.

Gunther, M. (2015). Auftragstaktik: the basis for modern military command, Pickele Partners Publishing.

Greenberg, J. (1990). Looking fair vs. being fair: Managing impressions of organizational justice, In B.M. Staw and L.L. Cummings (Eds.), Research in organizational behavior 12, pp.111-157.

Holmes, J-M. (2011). Defining adaptative leadership in the context of mission command. US Army command and general staff college, Fort Leavenworth.

Kakutani, S. (1941). A generalization of Brouwer's fixed point theorem, Duke Mathematical Journal 8(3), pp.457-459.

Keller, L. (2003). Le rôle du supérieur hiérarchique dans la démotivation des salariés, Recherche et action 3.

Lacan, A. (2016). La postmodernité dans l'entreprise : quel manager pour relever le défi? Management et avenir 90, pp.195-217.

Mejri, S. (2009). L'approche discursive, une nouvelle perspective pour la recherche en stratégie, Synergie Tunisie 1, pp.187-208.

Mongin, P. (2008). Retour à Waterloo, Annales, Histoires et sciences sociales 63(1), pp.39-69.

Millotat, C. (2001). Auftragstaktik, das oberste Führungsprinzip im Heer der Bundeswehr. Österreichische Militärische Zeitschrift, 3.

Application of Game Theory in Middle-Management: A Military Historical Study of the Role of the Middle-Manager as a Correlated Equilibrium Factor in the Decision-Making Process 
Mintzberg, H. (1973), The nature of managerial work, Prentice Hall, Upper saddle river New Jersey.

Mintzberg, H. (1973), Strategy-making in three modes, California management review 16(2), pp. 43-53.

Mintzberg, H. (1984). Le manager au quotidien, les dix rôles du cadre. Editions d'Organisation, Paris.

Rosseels, G. (2012). Moltke's Mission Command Philosophy in the Twenty-First Century: Fallacy or Verity? ARMY COMMAND AND GENERAL STAFF COLL FORT LEAVENWORTH KS.

Schmidt, C. (2006). Deux prix Nobel pour la théorie des jeux, Revue d'économie politique 116(2), p.133-145.

Simon, H. A. (1986). Rationality in psychology and economics. The Journal of Business Part 2: The Behavioral Foundations of Economic 59(4), p. 209-224.

Shamir, E. (2010). The long and winding road: the US Army managerial approach to command and the adoption of Mission Command (Auftragstaktik), The Journal of Strategic Studies 33(5), pp.645-672.

Steiber, A., \& Alänge, S. (2016). The Silicon Valley Model. In The Silicon Valley Model (pp. 143-155). Springer, Cham.

Stimec, A. (2008). Le manager médiateur: une figure méconnue. Humanisme et Entreprise, 289(4), pp. 105-118.

Walliser, B. (1989). Théorie des jeux et genèse des institutions. Recherches Économiques de Louvain/Louvain Economic Review, 339-364.

Walliser, B. (2002). Les justifications des notions d'équilibre de jeux. Revue d'économie politique 112(5), pp.693-716.

Wert, J. (2015). Gettysburg, day three, Simon and Schuster.

Wieviorka, M. (1992). Case studies: History or sociology. What is a case, pp. 159-172.

Yakovleff, M. (2006). Tactique théorique. Paris: Economica.

Yin, R. K. (2003). Design and methods. Case study research 3(9.2).

Application of Game Theory in Middle-Management: A Military Historical Study of the Role of the Middle-Manager as a Correlated Equilibrium Factor in the Decision-Making Process 